\title{
Peran Aktor Eksternal Dalam Pengembangan Pariwisata Di Desa Wisata Samiran Kecamatan Selo, Kabupaten Boyolali
}

Dewi Nurkhayani a, 1 , I Made Adikampana a, 2

1dewikhay@gmail.com, 2 adikampana@unud.ac.id

a Program Studi S1 Destinasi Pariwisata, Fakultas Pariwisata,Universitas Udayana, Jl. Dr. R. Goris, Denpasar, Bali 80232 Indonesia

\section{Abstract}

This research was to analyze The Role of External Agent to Tourism Development of Samiran Tourism Village. Samiran Tourism Village become mainstay tourism attraction at Boyolali Regency. Samiran Tourism Village have natural potential namely Merapi mountain dan Merbabu, Samiran Tourism Village is located on slope of the mountain. The development of Samiran Tourism Village is so rapid, as evidenced by the achievement that 3rd national champion in prestigious event of Tourism Village Competition held by the Ministry of Tourism and Creative Economy. The successfull of Samiran Tourism Village today, because of the high participation of local communities. But, who would have thought tucked into role of external agent in the development. The external agent to become a director in the development of Samiran Tourism Village.

This research conducted using qualitative methods, described through descriptive teqniques, data were collected through observation and depth interview on the informant. Selection of informant invitation purposive sampling technique.

This study shows the role of external agent as a drafter, the mouthpiece in the information and tourism ambassador in the tourism development at the Samiran Tourism Village. Existing barriers be addressed to the quite and preferably local communities, especially younger generation must be learh how to be independent tourism area, in order to avoid dependency on external agent.

Keywords: Role, External Agent, Rural Tourism, Tourism Village

\section{PENDAHULUAN}

Pada tahun 2012 tercatat sebanyak 967 Desa Wisata yang tersebar diseluruh Indonesia, jumlah yang cukup fantastis (bukutahu.com). Desa Wisata banyak tesebar di Provinsi Jawa Tengah, DIY dan Bali. Desa Wisata banyak dikembangkan oleh beberapa negara berkembang, sama halnya dengan di Indonesia, mulai dari Desa Wisata yang benar-benar memiliki potensi atau hanya sekadar latah mengikuti trend semata, sehingga akhirnya Desa Wisata tersebut tidak akan mampu bersaing dan akhirnya vakum dengan sendirinya. Program pemerintah pada tahun 2002 sebagai tahun Ekowisata membuka jalan bagi masyarakat dan pemerintah untuk mengembangan potensi Desa yang dimiliki sebagai Desa Wisata. Program Pemerintah melalui PNPM Mandiri yang memeberikan hibah bagi 900 Desa di seluruh Indonesia. Desa Wisata kini menjadi pundi-pundi rupiah bagi masyarakat lokal, pariwisata kini bisa menjadi pekerjaan sampingan (side job) masyarakat lokal. Masyarakat lokal sangat diuntungkan dengan adanya kegiatan pariwisata di Desa mereka, karena mendapatkan keuntungan secara langsung (benefit). Partisipasi masyarakat dalam kegiatan pariwisata tentunya juga dapat meningkatkan taraf hidup masyarakat lokal, untuk tercapainya pariwisata yang berkelanjutan (Sustainable Tourism) yang nantinya dapat diwariskan pada generasi selanjutnya. Apabila masyarakat lokal memiliki rasa (handar beni) atau rasa memiliki, maka masyarakat lokal akan menjaga sumber daya dengan baik dan tidak akan merusaknya.

Desa Wisata Samiran merupakan salah satu Desa Wisata yang berada di Kabupaten Boyolali yang menjadi Desa Wisata andalan di Provinsi Jawa Tengah. Desa Wisata Samiran memiliki pemandangan yang elok, asri dengan landscape pegunungan. Desa Wisata Samiran berada disela-sela atau dilereng Gunung Merapi dan Gunung Merbabu. Desa Wisata Samiran mengembangkan konsep pengembangan pariwisata berbasis masyarakat lokal ( Community Based Tourism Development). Masyarakat lokal memiliki peran dalam pengambilan keputusan dan pembagian hasil (sharing benefit). Terbukti dengan prestasi yang diraih Desa Wisata Samiran mendapatkan juara III dalam Lomba Desa Wisata Tingkat Nasional yang diselenggarakan oleh Kementerian Pariwisata dan Ekonomi Kreatif pada tahun 2013. Prestasi yang diraih oleh Desa Wisata Samiran adalah hasil kerja keras masyarakat lokal serta tidak lepas dari peran aktor 
eksternal yang cukup tinggi. Karena hal itu, dalam penelitian ini berfokus pada bagaimana peran aktor eksternal dalam pengembangan Desa Wisata Samiran? Tujuan dari penelitian ini untuk mengetahui bagaimana peran aktor eksternal dalam pengembangan Desa Wisata Samiran, Kecamatan Selo, Kabupaten Boyolali.

\section{TINJAUAN PUSTAKA}

Tinjauan penelitian sebelumnya yang dijadikan relevan untuk referensi dalam penelitian ini adalah Tesis Dayang Nevia Afriansari "Peran Kelompok Perempuan Dalam Pengelolaan Desa Wisata Samiran, Selo, Boyolali" (2013). Penelitian memiliki kesamaan lokus yaitu Desa Wisata Samiran. Penelitian yang memiliki fokus peran juga terdapat pada skripsi Fickyana Setyaratih " Peran Pemerintah Dalam Mengembangkan Potensi Wisata Museum (Studi Kasus Museum Senobudoyo, Yogjakarta)" (2013). Konsep yang digunakan dalam penelitian ini adalah

\section{a. Konsep Peran:}

Menurut Soekanto (2002) peran merupakan aspek dinamis kedudukan (status). Apabila seseorang melaksanakan hak dan kewajibannya sesuai dengan kedudukannya, ia menjalankan perannya.

\section{b. Konsep Aktor Ekstenal}

"An external agent is person, organization, or system with which a bussiness area interact" Carkenord (2009). Eksternal agent sering juag disebut sebagai aktor eksternal. Dalam penelitian ini, penulis menggunakan istilah aktor eksternal. Jadi aktor eksternal dalam penelitian ini adalah sesorang yang bukan masyarakat lokal Desa Wisata Samiran. Yaitu Ibu Dayang selaku ketua tim pengelola Desa Wisata Samiran.

\section{c. Konsep Pengembangan Pariwisata}

Menurut Paturusi (2001) pengembangan merupakan suatu strategi yang digunakan untuk memajukan, memperbaiki dan meningkatkan kondisi kepariwisataan suatu objek dan daya tarik wisata sehingga dapat dikunjungi wisatawan serta mampu memberi manfaat bagi masyarakat sekitar daya tarik wisata maupun bagi pemerintah. Menurut Gamal Suwantoro (2004) Pengembangan pariwisata sering dikaitkan dengan Sapta Pengembangan Kebijakan oleh pemerintah yaitu : Promosi, aksesibilitas, kawasan pariwisata, wisata bahari, produk wisata, sumber daya manusia dan kampanye nasional sadar wisata.

Pengembangan pariwisata dalam penelitian ini adalah meningkatkan dan mengembangkan potensi yang dimiliki Desa Wisata Samiran yang mencakup SDM, produk wisata, promosi dan kampanye sadar wisata.

\section{METODE PENELITIAN}

Pemilihan Desa Wisata Samiran sebagai lokasi penelitian karena, Desa Wisata Samiran berada diwilayah Kabupaten Boyolali sehingga deket dengan peneliti yang berasal dari Boyolali, sehingga akses data cukup mudah.

Untuk memperjelas dan membatasi permasalahan dalam penelitian ini, maka ruang lingkup peran aktor eksternal yaitu kegiatan yang dilakukan oleh seorang (Ibu Dayang) dalam mengembangkan Desa Wisata Samiran. Sumber data yang digunakan yaitu, data primer yang diperoleh dari sumber-sumber primer, yakni yang asli, informasi dari tangan pertama pada saat peneliti berada dilapangan berdasarkan Wardiyanta (2010), Ibu Dayang selaku aktor eksternal (Ketua Pengelola Desa Wisata Samiran) adalah informan tangan pertama, sedangkan data sekuder berasal dari dokumen-dokumen yang dimiliki pengelola Desa Wisata Samiran, jurnal yang relevan dan dokumen dari instansi terkait. Teknik pengumpulan data dalam penelitian ini menggunakan Sugiyono (2014) dengan cara: wawancara mendalam, observasi dan studi kepustakaan. Sedangkan untuk teknik penentuan informan menurut Sugiyono (2014) Purposive sampling merupakan pengambilan sampel sumber dengan pertimbangan tertentu, yaitu Ibu Dayang selaku aktor eksternal yang paham akan peranannya di Desa Wisata Samiran.

Penelitian mengenai peran aktor eksternal dalam pengembangan Desa Wisata Samiran, Kecamatan Selo, Kabupaten Boyolali ini menggunakan metode penelitian deskriptif kualitatif. Menurut Bogman dan Biklen (1982) dalam Moleong (2007), adalah upaya yang dilakukan dengan jalan bekerja dengan data, mengorganisasikan data, memilah-melahnya menjadi satuan yang dapat dikelola, mensintesiskannya, mencari dan menemukan pola, menemukan apa yang penting dan apa yang dipelajari, dan memutuskan apa yang dapat dipelajari, dan memutuskan apa yang 
dapat diceriterakan kepada orang lain. Berdasarkan pada uraian diatas dapat disimpulkan bahwa, langwah awal dalam analisis data yaitu mengumpulkan data, dirangkum secara sistematis dan menyapaikan/mempresentasikannya kepada orang lain secara jelas.

\section{HASIL DAN PEMBAHASAN}

Masyarakat lokal Desa Wisata Samiran berhasil bersinergi dangan aktor ekstenal dalam mengembangakan potensi yang dimiliki. Penghargan tingkat provinsi maupun nasional berhasil digondo, sebagai contoh juara 3 tingkat Nasional lomba Desa Wisata yang diselenggarakan oleh Kementerian Pariwisata dan Ekonomi Kreatif tahun 2013. Dari awal pembentukkannya Desa Wisata Samiran berusaha menerapkan konsep Community Based Tourism (CBT) yang mengedepankan masyarakat lokal sebagai tuan rumah. Masyarakat lokal mendapatkan benefit secara langsung dengan adanya kegiatan pariwisata. Keberhasilan Desa Wisata Samiran tidak semata-mata karena partisipasi masyarkat lokal yang cukup tinggi, namun ada konseptor dibalik kesuksesan yang diperoleh saat ini.

Ibu Dayang sebagai orang luar (aktor eksternal) berhasil masuk ke dalam komponen masyarakat Desa Wisata Samiran. Yang berhasil mensutradarai masyarakat lokal dalam meningkatkan kesejahteraan masyarakat, tanpa meninggalkan perkerjaan asli masyarakat lokal yaitu sebagai petani tembakau dan sayuran.

\section{Pengembangan Desa Wisata Samiran}

Desa Wisata Samiran berdiri sejak tahun 2002, namun pada awal pengembangannya, Desa Samiran belum terbentuk sebagai Desa Wisata. Kepengurusan dipegang oleh Pokdarwis "Guyup Rukun". Pokdarwis Guyup Rukun beranggotakan masyarakat lokal yang memiliki kesadaran akan adanya potensi yang dimiliki Desa Samiran, terdiri dari berbagai latar belakang pekerjaan. Pada tahun 2006, mulai dikembangkan menjadi rintisan Desa Wisata, tim pengelola Desa Wisata menyusun berbagai alternatif aktifitas yang dapat dilakukan di Desa Samiran.

Menurut Nurkhayani

Perkembangan Desa Wisata Samiran berada dilevel pembangunan (development), hal ini menunjukkan bahwa Desa Wisata Samiran pada level ini masih banyak sektor yang harus diperbaiki dan dikembangkan. Pengembangan Desa Wisata Samiran antara lain:

a. Terbentuk tim pengelola Desa Wisata Samiran yang dahulunya dipegang oleh Pokdarwis, saat ini dikelola oleh Pengelola Desa Wisata Samiran. Terbentuk kelompokkelompok wanita tani, kelompok homestay hingga kelompok kesenian. Tujuan dari pembentukkan kelompok ini bertujuan untuk memudahkan dalam kontrol, evaluasi, serta mendapatkan bantuan dari pemerintah. Hal ini juga sesuai dengan konsep pariwisata berbasis masyarakat yang diterapkan di Desa Wisata Samiran.

b. Peningkatan kualitas Sumber Daya Manusia (SDM) masyarakat lokal Desa Wisata Samiran, yaitu dengan cara mengikutsertakan ibu-ibu pengurus homestay dalam pelatihan yang diakan oleh pengelola Desa Wisata Samiran dan pemerintah kabupaten Boyolali. Selain itu, ada pembinaan terhadap kelompok-kelopok tani dan dan ternak melalui penyuluhan.

c. Promosi pariwisata

Promosi pariwisata dilakukan dengan berbagai cara, kemajuan teknologi saat ini memudahkan masyarakat dan pengelola Desa Wisata Samiran dalam mempromosikan dan memasarkan produk. Menjalin hubungan yang baik dengan pemerintah dan industri (ASITA Jogja dan Jateng) membuat pemasaran produk Desa Wisata Samiran cukup mudah. Jika dahulu, Desa Samiran hanya menjadi Desa Transit sebelum melakukan pendakian menuju Gunung Merapi maupun Merbabu, kini menjadi salah satu daerah tujuan wisata. Forum Komunikasi Desa Wisata se-Jateng (FK Deswita Jateng) sebagai ajang promosi yang sangat ampuh. Promosi juga dilakukan memalui beberapa akun sosial media, Facebook, Instagram dan website.

d. Pengembangkan produk wisata, mengemas produk pariwisata Desa Wisata Samiran dengan baik menjadi sangat penting. Karena produk merupakan sesuatu yang dijual kepada wisatawan. Pengembangan produk pariwisata, adanya pilihan paket wisata diantaranya, agrowisata, wisata perah susu sapi, live in, outbond, soft trekking, dan mendaki gunung. Produk wisata nyatanya tidak melulu dengan hal yang terlihat namun hospitality, kearifan lokal masyarakt lokal juga merupakan suatu produk pariwisata yang terus dikembangkan. 
e. Kampanye sadar wisata. Sadar wisata tentu sangat mutlak diperlukan dalam pengembangan suatu daya tarik wisata, sama halnya dengan Desa Wisata Samiran. Kelompok Sadar

Wisata (Pokdarwis) "Guyup Rukun" telah terbentuk pada tahun 2002, diprakarsai oleh beberapa tokoh di Desa Samiran diantaranya, Pak Tris dan Pak Sarjono. Pokdarwis Guyup Rukun terbentuk oleh kesadaran masyarakat lokal dengan adanya potensi yang dimiliki oleh Desa Wisata Samiran. Selain itu, pada tahun 2002 dicangkan oleh presiden Megawati Soekarno Putri sebagai tahun Ekowisata. Karena adanya dorongan dari pemerintah pusat dan potensi yang dimiliki maka terbentuklah Pokdarwis. Pokdarwis ini selanjutnya berfungsi sebagai pengelola, perencana dan mengontrol kegiatan pariwisata di Desa Wisata Samiran.

\section{Pihak-pihak yang berperan dalam pengembangan Desa Wisata Samiran}

Pengembangan suatu daya tarik wisata tidak terlepas dari peran pihak-pihak yang terkait. Berkembang atau tidaknya suatu daya tarik wisata tergantung pada sinergi antara masyarakat lokal, industri pariwisata dan pemerintah. Masyarakat lokal sebagai tuan rumah atau pemilik sumber daya, menjadi penting dalam hal ini. Masyarakat lokal Desa Wisata Samiran sebagian besar berprofesi sebagai petani, memiliki kekurangan dalam mengelola potensi yang ada. Peran masyarakat lokal sangat tinggi dalam pengembangan Desa Wisata Samiran, masyarakat lokal berperan sebagai perencana, pengelola, evalusi dan memperoleh benefit secara langsung. Dengan dukungan dari pemerintah Kabupaten Boyolali, kepariwisataan di Desa Wisata Samiran semakin populer. Dengan turunnya SK pembentukan Desa Wisata oleh Kepala Dinas Kebudayaan dan Pariwisata Kabupaten Boyolali 552/881/17/TAHUN 2009, sehingga keberadaan Desa Wisata Samiran diakui secara hukum. Peran industri pariwisata juga cukup besar dalam mempromosikan Desa Wisata Samiran. Namun, selain dari peran dari stakeholder, terselip kontribusi seorang aktor eksternal yang sangat besar. Aktor eksternal disini berfungsi sebagai sutradara atau konseptor dalam pengembangan pariwisata di Desa Wisata Samiran. Ibu Dayang, aktor eksternal yang setia dalam perintisan Desa Samiran menjadi Desa Wisata Samiran.

\section{Peran Aktor Eksternal dalam Pengembangan Pariwisata di Desa Wisata Samiran}

Partisipasi masyarakat lokal Desa Wisata Samiran sangat besar, namun kontribusi aktor eksternal juga sama besarnya. Sinergi yang baik antara masyarakat lokal Desa Wisata Samiran dengan aktor ekstenal, membuat Desa Wisata Samiran memperoleh penghargaan sebagai Desa Wisata terbaik ketiga pada lomba Desa Wisata tingkat Nasional pada tahun 2013 yang diselenggarakan oleh Kementerian Pariwisata dan Ekonomi Kreatif. Partisipasi masyarakat lokal Desa Wisata Samiran berada pada tingkat terdorong (induced participation), Nurkhayani (2016). Pada awal terbentuknya Desa Wisata Samiran, aktor eksternal menjabat sebagai wakil ketua tim pengelola Desa Wisata Samiran. Saat ini, aktor eksternal menjabat sebagai ketua tim pengelola Desa Wisata Samiran. Berikut adalah kontribusi yang diberikan oleh aktor eksternal:

a. Aktor eksternal sebagai konseptor atau sutradara, latar belakang pendidikan yang dikantongi aktor eksternal dibidang pariwisata membuat Ibu Dayang mengaplikasikan ilmu yang diperoleh diterapkan di Desa Wisata Samiran, yang notabenenya sebagai Desa binaannya.

b. Sebagai pioneer penerapan konsep pembangunan pariwisata berbasis masyarakat lokal (Community Based Tourism Development. Masyarakat lokal diikutsertakan dalam pengambilan keputusan dan sharing benefit. Segala sesuatu dari masyarakat lokal dan untuk masyarakat lokal.

c. Aktor Eksternal berperan sebagai penyambung lidah, letak geografis Desa Wisata Samiran yang berada di lereng gunung membuat akses informasi yang diperoleh tidak maksimal, aktor eksternal memiliki relasi yang yang cukup luas membuat informasi yang diperoleh begitu cepat.

d. Aktor eksternal mampu menjembatani antara masyarakat lokal dengan pelaku pariwisata.

e. Aktor eksternal juga berperan sebagai duta wisata Desa Samiran secara tidak 
langsung, karena kemana-manapun beliau pergi selalu membawa nama Desa Wisata Samiran, secara langsung maupun tidak langsung mempromosikan Desa Wisata Samiran.

Peran aktor eksternal tidak semata-mata berkonotasi yang negatif. Namun, dalam perkembangannya, nyatanya masyarakat lokal khususnya dipedesaan membutuhkan peran dari seorang aktor eksternal.

\section{Hambatan yang diperoleh Aktor Eksternal dalam Mengembangkan Pariwisata di Desa Wisata Samiran}

Mengelola sebuah suatu daya tarik wisata bukanlah pekerjaan yang mudah, sama halnya dengan yang dialami oleh Aktor Eksternal (Ibu Dayang) dalam menjalankan perannya, mengembangkan Desa Wisata Samiran. Pro dan kontra sering dihadapi. Berikut adalah beberapa hambatan yang dialami oleh Aktor Eksternal dalam mengembangkan Desa Wisata Samiran:

a. Sumber Daya Manusia, masyarakat lokal Desa Wisata Samiran sangat terbuka dengan masuknya Aktor Eksternal dalam pengelolaan Desa Samiran. Hal ini membawa angin segar bagi masyarakat lokal Desa Wisata Samiran. Masyarakat lokal terdidik bisa dihitung jumlahnya. Namun, masyarakat lokal Desa Wisata Samiran ada kemauan keras untuk belajar mengelola Desa Wisata dengan baik.

b. Cibiran dari beberapa orang yang tidak sejalan dengan Aktor Eksternal. Apalagi dengan status akor eksternal sebagai orang luar,bukan penduduk asli Desa Samiran.

\section{SIMPULAN DAN SARAN}

Berdasarkan hasil penelitian yang dilakukan di Desa Wisata Samiran dapat disimpulkan bahwa kesuksesan Desa Wisata Samiran yang saat ini diperoleh, ada kerjasama yang baik antara masyarakat lokal dengan aktor eksternal yang berfungsi sebagai konseptor. Peran aktor eksternal cukup besar dalam pengembangan Desa Wisata Samiran. Peran aktor eksternal dalam mendirikan Desa Wisata yang sebelumnya dikelola Pokdarwis, namun jalan ditempat. Keberadaan aktor eksternal mempunyai dampak yang positif untuk kemajuan Desa Wisata Samiran. Pro dan kontra nampaknya menjadi hal lumrah dalam seseorang menjalankan perannya. Aktor eksternal di Desa Wisata sampai saat ini masih mendampingi, tidak meninggalkan Desa binaannya walaupun Desa tersebut dapat berdiri sendiri. Kedekatan antara masyarakat lokal Desa Wisata Samiran dan aktor eksternal menjadikan tali silaturahmi yang sangat baik, aktor eksternal seakan-akan menjadi masyarakat lokal Desa Wisata Samiran. Mereka melebur menjadi satu-kesatuan yang sangat apik.

Saran dalam penelitian yaitu, masyarakat lokal seyogyanya belajar untuk tidak mengantungkan diri pada aktor eksternal. Agar masyarakat lokal yang menjadi mandiri. Perlu adanya regenerasi kepemimpinan dan peningkatan SDM generasi muda di Desa Wisata Samiran harusbelajar dengan aktor eksternal bagaimana merencanakan dan mengelola Desa Wisata Samiran agar menjadi daya tarik wisata unggulan di Kabupaten Boyolali. Pelatihan juga perlu dilakukan oleh pengelola Desa Wisata Samiran, untuk mendidik generasi muda agar sadar akan potensi yang dimiliki Desa mereka, harus ada inisiatif dari pengelola Desa Wisata dengan kemauan generasi muda itu sendiri. Penelitian mengenai sinergi antara masyarakat lokal dengan aktor eksternal eksternal di Desa Wisata Samiran, menarik untuk dilakukan.

\section{Daftar Pustaka:}

Bogdan, R.C dan Biklen, S.K. 1982. "Qualitative Reasearch for Education: An Introduction to Theory and Methods" dalam Moleong. Lexy J (ed). 2007. Metodologi Penelitian Kualitatif. Bandung: PT Remaja Rosdakarya Offset.

Carkenord, Barbara A. 2009. Seven Steps To Mastering. Business Analysis. Florida: J. Ross Publishing.

Ficyana, Setyaratih. 2013. Peran Pemerintah Dalam Mengembangkan Potensi Wisata Museum (Studi Kasus Museum Senobudoyo, Yogjakarta). Jogjakarta: Universitas Negeri Yogjakarta.

Nevia Afriansari, Dayang. 2013. Peran Kelompok Perempuan Dalam Pengelolaan Desa Wisata Samiran, Selo, Boyolali. Jogkarta: Universitas Gadjah Mada.

Nurkhayani, Dewi. 2016. Partisipasi Masyarakat Lokal Terhadap Perkembangan Pariwisata di Desa Wisata Samiran, Kec Selo, Kab. Boyolali. Bali: Fakultas Pariwisata, Universitas Udayana.

Paturusi. Samsul A. 2001. Perencana Tata Ruang Kawasan Pariwisata, Materi Kuliah Perencanaan Pariwisata, Program Pasca Sarjana. Bali: Universitas Udayana.

Soekamto, Soerjono. 1990. Sosiologi Suatu Pengantar. Jakarta: CV. Rajawali 
Vol. 5 No 1, 2017

Sugiyono. 2014. Metode Penelitian Kombinasi (Mixed Methods). Bandung: Alfabeta.

Suwantoro, Gamal. 2004. Dasar-Dasar Pariwisata. Yogjakarta. Andi.

Wardiyanta, 2006. Metode Penelitian Pariwisata. Yogjakarta: Andi.

10 Desa Wisata di Indonesia

http://www.bukutahu.com/2014/12/10-desa-wisata-diindonesia.html (Akses: 2016, Oktober 2) 